\title{
EU ESFOLADO EM LUGAR VAGAMENTE desconfortável: Bruce Nauman, Samuel BECKETT, O DESPOVOADOR
}

\author{
LILIANE BENETTI \\ Universidade de São Paulo
}

\section{Resumo}

Guardadas as diferenças relativas à distância geracional e às especificidades dos campos disciplinares, algumas convergências formais e temáticas são observadas entre as obras de Samuel Beckett (1906-1989) e de Bruce Nauman (1941). Este ensaio busca aproximá-las tendo em conta os escritos de Nauman para suas primeiras instalações artísticas e $O$ Despovoador, pequeno texto em prosa publicado por Beckett em 1970.

Abstract

In spite of generational gap and disciplinary field specificities, it is possible to point some formal and thematic convergences between Samuel Beckett's pieces and Bruce Nauman's works of art. This essay aims at comparing them with an emphasis on Nauman's texts for his first art installations and The Lost Ones, Beckett's small prose published in 1970.

Palavra-chave:

Samuel Beckett, Bruce Nauman, arte moderna e contemporânea, instalação, crítica de arte.

Keywords:

Samuel Beckett, Bruce Nauman, modern and contemporary art, installation art, art criticism. 
Dos ângulos de aproximação que podem ser traçados entre as obras de Samuel Beckett e Bruce Nauman ${ }^{1}$, artista plástico estadunidense atualmente com 72 anos, parte-se aqui de Silêncio Falso, texto escrito por Nauman, em 1975, por ocasião de um convite para exibir seus trabalhos, incipientes na época, em uma galeria de Los Angeles:

\section{SILÊNCIO FALSO}

Eu não transpiro

Eu não tenho odor

Eu inalo, não exalo

Sem urina

Eu não defeco: nenhuma excreção de qualquer tipo

Eu só consumo oxigênio, todas as comidas, qualquer forma

Eu vejo, ouço

Eu não falo, não produzo outros sons, você não pode ouvir meu coração, meus passos

Nenhuma expressão, nenhuma comunicação de qualquer tipo

Um observador, um consumidor, um usuário apenas

Meu corpo absorve todas as comunicações, emoções, absorve calor e frio

Super reptiliano absorvendo todo conhecimento, compactador de toda informação

Sem crescer

Eu sinto, não toque

Eu não tenho controle sobre os tipos e as qualidades dos pensamentos

Eu coleciono, eu não consigo processar

Eu não posso reagir ou agir com base em sensações

Sem resposta emocional às situações

Não há reação instintiva a ameaças físicas ou mentais

Você não pode me alcançar, você não pode me ferir

Eu posso sugá-lo até a última gota

Você não pode me ferir

Você não pode me ajudar

Embaralhe as páginas

Encontre para mim uma linha

Arapahoe, Arapahoe

Onde você foi

Eu pisco meus olhos para marcar o tempo. ${ }^{2}$

\footnotetext{
${ }^{1}$ É possível desdobrar homologias estruturais entre as produções de Bruce Nauman e Samuel Beckett, a despeito das muitas especificidades que as distinguem, além daquelas obviamente decorrentes da distância geracional e das particularidades de cada campo do conhecimento. Algumas das questões tratadas sucintamente neste artigo são abordadas nos capítulos da tese "Ângulos de uma caminhada lenta: exercícios de contenção, reiteração e saturação na obra de Bruce Nauman", sobretudo no terceiro e quarto capítulos [Cf. BENETTI, Liliane. Ângulos de uma caminhada lenta: exercícios de contenção, reiteração e saturação na obra de Bruce Nauman. 2013. 496p. Tese (Doutorado em História, Teoria e Crítica de Arte) - Escola de Comunicações e Artes da Universidade de São
} 
$\mathrm{O}$ artista ergueu numa das salas expositivas um corredor estreito de madeira e o iluminou com luzes fluorescentes brancas intensas, formalizando aquilo que comumente em artes visuais chama-se "instalação" - uma novidade nas décadas de 1960 e 1970. Dispôs no interior do espaço exíguo dois alto-falantes que transmitiam Silêncio Falso, texto gravado na íntegra por Nauman. Sua voz pausada e impassível descrevia um "algo" talvez humano, cujos processos físicos, psíquicos e fisiológicos encontravam-se transtornados: um corpo que drenava "até a última gota" de tudo o que dele se aproximava, em acumulação máxima; sem descompressão. Fisiologia incompleta, processos intelectivos e emocionais falhos. Algo a que ou a quem - não se discerne a despeito das palavras precisas - não se podia ferir, tampouco ajudar. Uma frieza vampirizante em desamparo. Dessa instalação não restou nenhum registro, sequer o fotográfico. O texto, no entanto, foi regravado por uma voz feminina para "Samuel Beckett/ Bruce Nauman", exposição que cotejou as duas produções e foi realizada em Viena, em $2003^{3}$.

Assim como Samuel Beckett explorou a literatura e a dramaturgia em romances, ensaios, poesia, enredos teatrais, textos curtos, além de peças para rádio e televisão, Bruce Nauman mostrava-se, desde o início de sua trajetória, permeável a múltiplas linguagens artísticas, dispondo de meios e materiais variados. Dedica-se, até hoje, à escultura, ao desenho, à fotografia, ao vídeo, à performance, à instalação, às intervenções arquitetônicas e urbanas note-se que apenas a pintura não está entre os gêneros.

Calibrando experimentação incessante e rigor formal, a obra de Nauman é uma das que alargou a própria noção de material no campo das artes visuais: além dos tradicionalmente utilizados na escultura, como mármore, granito, bronze, argila, cera, gesso, e daqueles incorporados ao repertório plástico desde a arte pop, como neon, resina, fibra de vidro, alumínio, borracha, feltro, entre tantos outros, os trabalhos de Nauman abarcam elementos associados a outras áreas do conhecimento, como a literatura, o teatro, a dança, o cinema. Textos escritos e falados, o corpo, os ruídos e vozes, o tempo, passam a figurar entre os materiais passíveis de manipulação. E, claro, a própria história da arte é tomada como material; aliás, as formas tradicionais têm sido pensadas como material desde, pelo menos, a arte moderna.

A peculiaridade de Nauman é submeter os materiais ao escrutínio rigoroso, testando-os no limite de exauri-los. Corpo, fibra de vidro, pedra, argila, pele, palavra, espaço, voz, grandes

Paulo, São Paulo, 2013. Disponível em: <http://www.teses.usp.br/teses/disponiveis/27/27160/tde-18112013163120/pt-br.php>].

2 No original: "FALSE SILENCE/ I don't sweat/ I have no odor/I inhale, don't exhale/ No urine/ I don't defecate: no excretions of any kind/ I consume only oxygen, all foods, any form/ I see, hear/ I don't speak, make no other sounds, you can't hear my heart, my footsteps/ No expression, no communication of any kind/ An observer, a consumer, a user only/ My body absorbs all communications, emotions, sucks up heat and cold/ Super reptilian soaking up all knowledge, compactor of all information/ Not growing/I feel don't touch/I have no control over the kinds and qualities of thoughts/ I collect, I can't process/ I can't react or act on sensation/ No emotional response to situations/ There is no reaction of instinct to physical or mental threats/You can't reach me, you can't hurt mel I can suck you dry/ You can't hurt me you can't help me/ Shuffle the pages find me a line/ Arapahoe, Arapahoe/ Where did you go/ I blink my eyes to keep the time". Os textos de Bruce Nauman que aparecem neste artigo foram traduzidos pela autora.

3 A mostra foi realizada entre 4 de fevereiro e 30 de abril de 2000 e contou com a curadoria de Christine Hoffmann e Michael Glasmeier [Cf. GLASMEIER, Michael \& HOFFMANN, Christine (Orgs.). Samuel Beckett, Bruce Nauman. Viena: Kunsthalle, 2000]. Já em 2007, na comemoração dos trinta anos do Centre Pompidou, em Paris, realizou-se uma exposição inteiramente dedicada a Samuel Beckett, em cujo catálogo há referências à obra de Bruce Nauman [Cf. ALPHANT, Marianne \& LEGER, Nathalie (Orgs.). Object Beckett. Paris: Centre Pompidou/ Imec Éditeur, 2007]. 


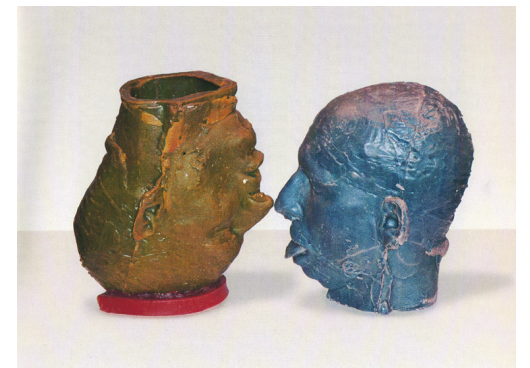

1 Andrew Head/Andrew Head Reversed/, Nose to Nose, 1990, cera, dimensões variáveis. ${ }^{\oplus}$ Bruce Nauman; crédito fotográfico ${ }^{\circledR}$ Bruce Nauman studio.

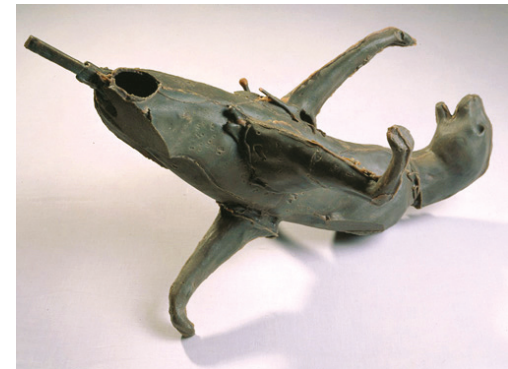

2 Blue Cat, 1989, cera, $71,4 \times 52,1 \times 59,9 \mathrm{~cm}$. () Bruce Nauman; crédito fotográfico ${ }^{\circledR}$ Donald Young Gallery.

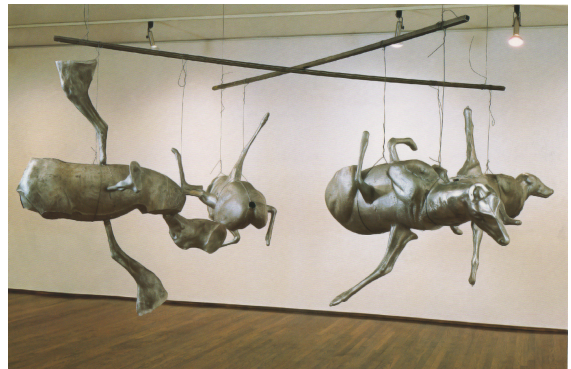

3 Four Large Part Animals, 1989, alumínio, tubos de ferro, $142 \times 376 \times 368 \mathrm{~cm}$. ${ }^{\oplus}$ Bruce Nauman; crédito fotográfico (๑)

temas da condição humana, referências pop ou citações de artistas, filósofos, músicos: tudo é tratado indistintamente como material bruto, de modo franco e direto. Não se preservam vestígios de sentido, essência ou interioridade que não possam ser subitamente virados do avesso e expostos. A inversão entre interior e exterior, entre continente e conteúdo, a equivalência de estatuto entre materiais de natureza e densidades diversas, entre o orgânico e o inorgânico e a contiguidade de superfícies são procedimentos recorrentes na obra.

O propósito declarado da obra de Nauman é o de tornar as coisas mais simples e menos importantes, descobrir o modo correto, direto, franco para apresentar ideias. Como metáfora daquilo que pretende com sua obra, Nauman recorre à imagem do nocaute por uma pancada violenta na nuca, certeira, imprevisível e inescapável ${ }^{4}$. Em suas palavras, "quando algo está suficientemente terminado para que eu apreenda, quando a questão está clara, então nada mais é necessário, nenhum acabamento. Precisa ser bem feito o suficiente para comunicar." Não à
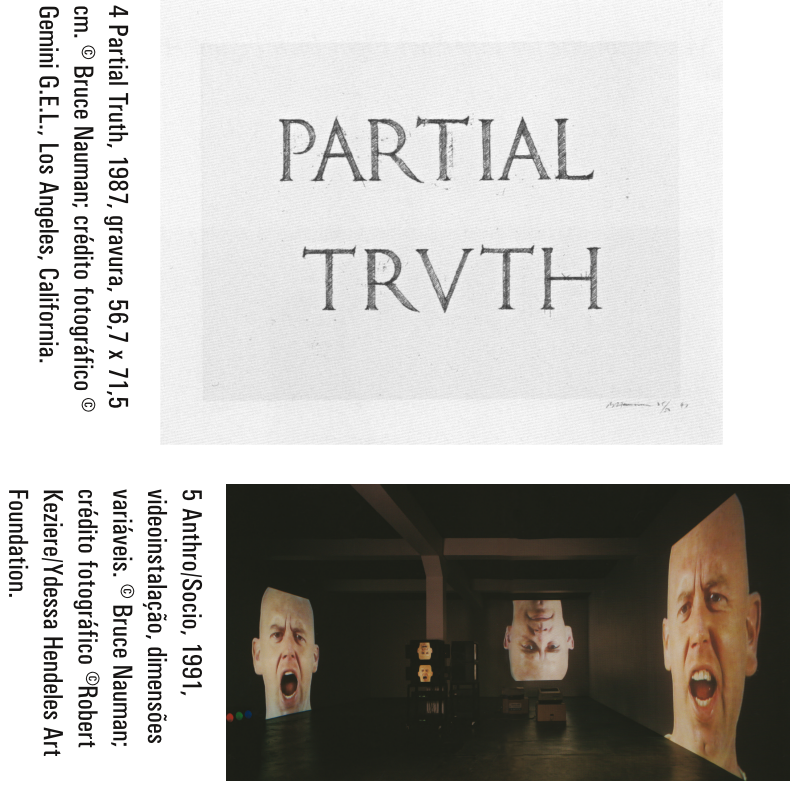

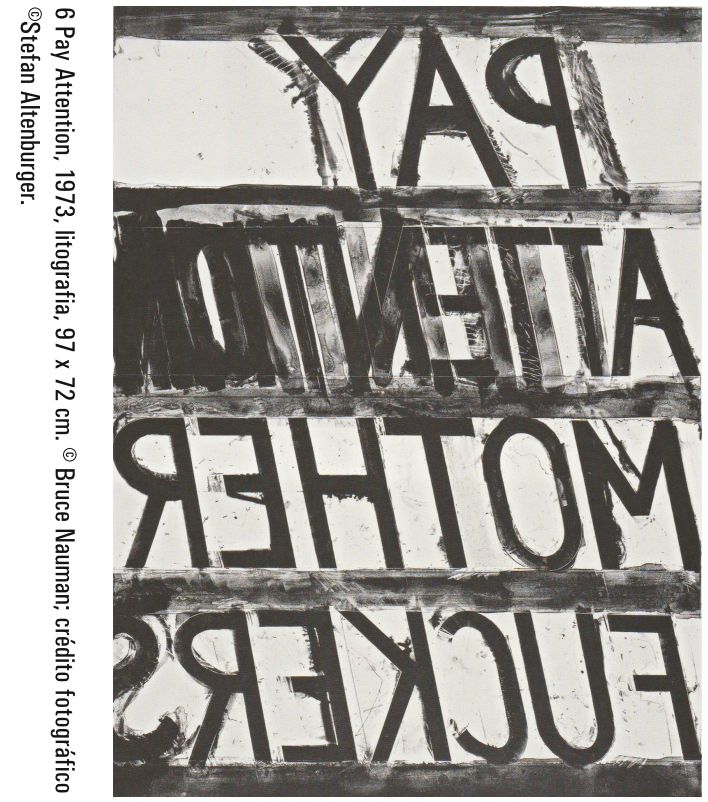

4 "From the beginning I was trying to see if I could make art that [... is] like getting hit in the face with a baseball bat, like getting hit in the back of the neck. You never see it coming, it just knocks you down. I like the idea very much: the kind of intensity that doesn't give you any trace of whether you're going to like it or not'. Cf. KRAYNAK, Janet (Ed.). Please pay attention please: Bruce Nauman's words: writings and interviews. Cambridge, Massachusetts: The MIT Press, 2005, p. 320.

5 "When it's finished far enough so that I apprehend, so that the point is clear [...] then it doesn't need any more finish work. It needs to be made well enough to communicate. I very seldom can work with anyone else, because when it gets that point where I can say, 'now I know what's going on, you can finish it', it doesn't need any more finishing". Cf. Id., ibidem, p. 208. 


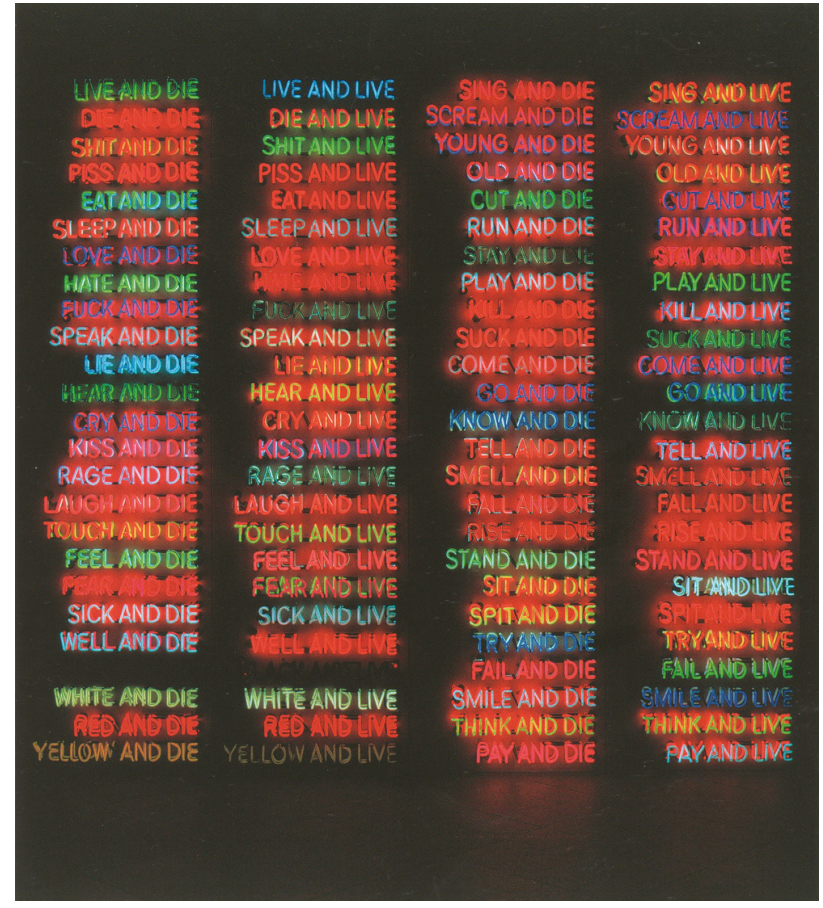

7100 Live and Die, 1984, tubos de neon, 300 x 336 x $53 \mathrm{~cm}$. ${ }^{\oplus}$ Bruce Nauman; crédito fotográfico ${ }^{\circledR}$ Donald Young Gallery. toa, suas esculturas têm aspecto rústico, superfícies grosseiramente rematadas, pois aquilo que se entende por acabamento das peças seria, nos trabalhos de Nauman, um pós-acabamento supérfluo que comprometeria a execução precisa da ideia. Voltado às palavras, tal propósito resulta em uma linguagem tão crua que chega a ser crassa, rude: frases curtas, estrutura direta, sem volteios retóricos ou loquacidade fora do lugar. Sujeito, verbo, complemento. Ou só verbos e conectivos. Ou apenas uma sentença, uma palavra, um fonema repetidos à exaustão. Palavras são ritmadas nervosamente em neons de colorido pop, gravadas em chapas de metal, inscritas em pedras de aspecto tumular; são pronunciadas aos berros ou balbucios por cabeças-falantes, recitadas em cantilenas tediosas ou marteladas agressivamente por repetição; podem ser impostadas por um cantor de ópera ou então vocalizadas como um exercício amador; são emitidas como comandos estritos a que se deve obedecer ou servem às cenas simuladas de vaudeville, aos contos jocosos e piadas sem graça; vão das tolices aos palavrões, da neutralidade quase científica às obscenidades mais chulas. Há propostas de trabalhos inexequíveis, rubricas para atores, instruções para exercícios físicos que exigem habilidade incomum ou treinamento espartano e diretivas para performances mentais. Aparecem em desenhos, gravuras, esculturas, filmes e vídeos, gravações de áudio ou projeções no espaço. As palavras de Nauman descrevem, cumprimentam, agradecem, mentem, ordenam, humilham, constatam, falseiam, praguejam, suplicam, agridem.

Na década de 1970, a produção textual de Nauman é intensa e variada, e a escrita é

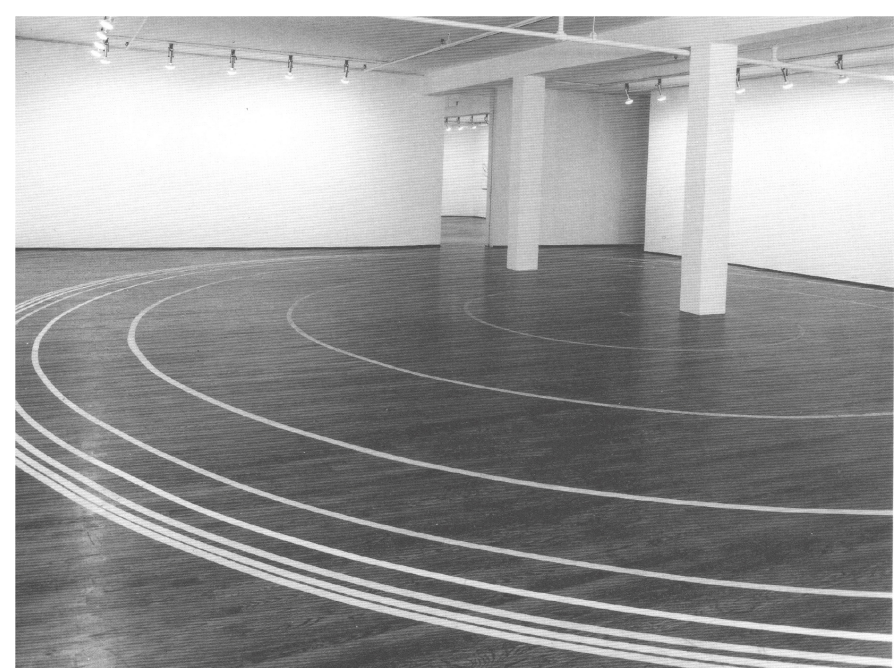
deliberadamente fragmentada e elíptica. Muitos são os textos que, como Silêncio Falso, acompanham as primeiras instalações do artista. Com tais textos, pretendia construir um lugar intermediário, a um só tempo física e linguisticamente engendrado. $\mathrm{O}$ propósito era o de realçar a relação disjuntiva que os textos mantinham com os elementos "físicos" dos trabalhos, mas jamais explicá-los. Frequentemente a arquitetura é tomada como metáfora do corpo e a escala é sempre a humana. Forjam-se correlações entre o espaço ๑Bruce C. Jones/ Leo Castelli Gallery. 
físico e o "espaço mental e psíquico", e transtornam-se ambos. Tais instalações propunham ativar o espaço expositivo alterando padrões perceptivos, quer por meio de interferências sutis como a intensificação da luminosidade de um ambiente ou a feitura de desenhos distorcidos em fita adesiva no chão, quer por meio de intervenções mais ostensivas na arquitetura, como o erguimento de paredes e a construção de recintos incongruentes.

Em lugar de acelerar a imersão nos espaços, os textos tendiam a ser óbices para o suposto imediatismo da experiência física a que pudessem convocar. Perturbavam, conforme depoimentos colhidos na época ${ }^{6}$, pelas oscilações abruptas de escala - ora referida às moléculas do corpo ora às grandezas astronômicas - e pela justaposição de temporalidades destoantes - que transitavam da volatilidade dos pensamentos ao vagar geológico, da propulsão vascular aos ritmos submarinos. Textos e ambientes procediam como informações enviesadas umas em relação às outras, nem corroborantes nem contraditórias, nas palavras de Nauman, comportavam-se como "linhas de enviesamento ou distorção: nunca se encontram e não são paralelas no espaço, mas podem estar muito próximas ou muito distantes." ${ }^{7}$ Cumpriam funções semelhantes, desabituavam a experiência de percepção do espaço e causavam incômodos em graus variados. Textos e ambientes juntos geravam o desconforto desafiador pretendido por Nauman ao propugnar por "uma arte que leva você ao limite, e o obriga a uma maior consciência de si mesmo e da situação. Muitas vezes, sem que você saiba o que está enfrentando e/ou vivenciando. Tudo o que se sabe é que se está sendo empurrado para um lugar com o qual não se está acostumado e que há alguma forma de ansiedade envolvida nisso."8 Afinal, Nauman busca, desde sempre, perturbar ou mesmo inviabilizar a relação contemplativa do observador com sua obra; nela, nada é reconfortante ou terapêutico.

Veja-se Instalação com Luzes Amarelas, trabalho de 1971 acompanhado do texto Left or Standing/ Standing or Left Standing" (Deixado ou Em pél Em pé ou Deixado em pé). Um recinto trapezoidal excessivamente iluminado por lâmpadas fluorescentes amarelas foi construído no interior de uma galeria de arte em Nova York. Nauman afirmou que o ambiente precedeu e inspirou o texto: ao caminhar pelo lugar recém-montado, que contava tão somente com duas paredes paralelas e, além do mais, havia sido instalado em meio aos pilares preexistentes no espaço, Nauman detectou que a angulosidade da estrutura e a intensidade da iluminação geravam sensações físicas desconcertantes, e o esforço de compensação visual do amarelo fluorescente provocava a emissão de flashes arroxeados que terminavam por fatigar os olhos $^{9}$. Eis o texto impresso no convite da mostra e também deixado à disposição dos visitantes na entrada da galeria, no formato de pôster destacável:

${ }^{6}$ Cf. AUPING, Michael. Projection and Displacement. In: NAUMAN, Bruce. Bruce Nauman: Drawings for Installations. Nova York: Sperone Westwater, 2008, p. 7-12; BRUGGEN, Coosje van. Bruce Nauman. Nova York: Rizzoli International Publications, 1988; KRAYNAK, Janet (Ed.). Op. cit.; NAUMAN, Bruce. Bruce Nauman: Works from 1965-1972. Los Angeles/ Nova York/ Dusseldorf: Los Angeles County Museum of Art/ Whitney Museum of American Art/ Stadtische Kunsthalle, 1972; NAUMAN, Bruce. Raw materials. Londres: Tate Press, 2004.

7 "Skew lines never meet and are not parallel in space - but they can be very close together or very far apart" (excerto de "Appendix", texto escrito por Bruce Nauman em 1972).

8 "[...] an art that puts you on an edge; it forces you into a heightened awareness of yourself and the situation. Often without you knowing what it is that you're confronting and/or experiencing. All you know is that you're being pushed into a place that you're not used to and that there's an anxiety involved in that" (Cf. BRUGGEN, Coosje van. Op. cit., p. 194).

${ }^{9}$ Cf. NAUMAN, Bruce. Bruce Nauman: Drawings for Installations. Nova York: Sperone Westwater, 2008 , p. 26 e 28. 
Deixado ou Em pé

Sua precisão e exatidão sugerindo cortes limpos, deixando uma vacância, uma leve depressão física como se eu estivera em um lugar vagamente desconfortável por um período não muito longo mas indeterminável; não esperando.

Em pé ou Deixado em pé

Sua precisão e acuidade deixaram pequenos cortes nas pontas dos meus dedos ou sobre as costas das minhas mãos, sem qualquer necessidade de sentar-se, ou de retirar-se de qualquer outro modo. ${ }^{10}$

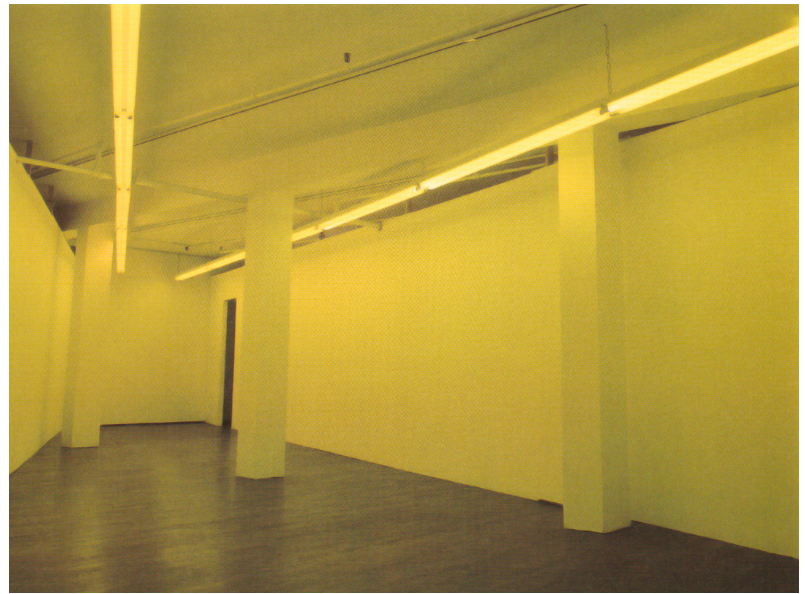

9. Installation with Yellow Lights, 1971, compensado e lâmpadas fluorescentes, dimensões variáveis. ${ }^{(}$Bruce Nauman; crédito fotográfico ${ }^{\circledR}$ Leo Castelli Gallery.

O texto curto parece projetar-se um pouco além ou, talvez, um pouco aquém dos fenômenos perceptivos estimulados pelo ambiente, evocando um estado de vacilante indefinição que conduz a sucessivas releituras; estas, imagina-se, em lugar de favorecer refreavam a experiência do espaço. A composição em duas partes e a repetição de certos termos em ambas, sugerem, num primeiro momento, uma relação especular ou uma complementaridade mutuamente esclarecedora, hipóteses afastadas tão logo se constata que os trechos mantêm-se encerrados neles mesmos, não se podendo derivar de um deles quaisquer consequências para o outro: são, a um só tempo, irredutíveis e lacunares, pois a precisão da linguagem retém a vagueza e a indefinição pretendida no conteúdo. Notável na construção poética é a cópula de termos tão marcadamente contrastantes quanto "precisão", "exatidão" e "acuidade" em face de "vacância", "lugar vagamente desconfortável" e "período não muito longo mas indeterminável". Embora não soubesse qual imagem poderia representar adequadamente as sensações instadas pelo amarelo intenso no interior de uma arquitetura pouco congruente, Nauman, em seu texto, buscou reforçar, ainda que de modo enviesado, a impressão de que aquele era o lugar errado para se estar. A desorientação física parecia agravada pelo texto lacunar, que estimulava vagamente a ansiedade já difusa no espaço. Nem surreal, nem absurdo, mas vagamente ansioso e desconfortável ${ }^{11}$. A escrita rigorosa mas enigmática, uma busca pela exatidão para, entretanto, designar lugares e situações intangíveis.

Nem surreal, nem absurdo, mas vagamente ansioso e desconfortável também é uma

10 "Left or Standing/ His precision and accuracy/ suggesting clean cuts, leaving/ a vacancy, a slight physical/ depression as though I had been/ in a vaguely uncomfortable placel for a not long but undeterminable/ period; not waiting. Standing or Left Standing/ His preciseness and acuity left/ small cuts on the tips of my/ fingers or across the backs of/ my hands without any need to sit or otherwise withdraw".

${ }^{11}$ Cf. AUPING, Michael. Metacommunicator. In: NAUMAN, Bruce. Raw Materials. Londres: Tate Press, 2004, p. 13. Também é de interesse o comentário de Emma Dexter que consta do mesmo catálogo, na página 20. 
maneira possível de referir-se ao texto em que são relatadas as ocorrências no interior de um cilindro emborrachado, de 50 metros de circunferência e 16 metros de altura, banhado por intensa e perene luz amarela, com temperatura variando entre 25 e 5 graus, onde Beckett encapsulou duzentas "criaturas", submetidas a condições excruciantes, ressequidas, em abstemia, padecendo processos intelectivos e emocionais falhos, presos a fisiologias transtornadas.

O despovoador (The Lost Ones /Le Dépeupleur), de Samuel Beckett, um pequeno texto em prosa, foi publicado em $1970^{12}$. Seu narrador é movido pelo rigor e esforça-se em um escrutínio o mais objetivo possível dos fatos observados, "pois só o cilindro oferece certezas e fora nada além de mistérios." 13 A escala do ambiente é inadequada para um convívio caso se pressuponha que os duzentos "fulanos" possam ser criaturas "algo" humanas. Não dispõem de espaço suficiente para mover-se sem que precisem roçar suas peles que, em função da incidência ininterrupta da luz amarela, tornam-se secas e amarelecidas; "apergaminham-se". Quando as superfícies entram em contato provocam sensações de aspereza, "os corpos se roçam com um ruído de folhas secas. As próprias mucosas sofrem com isso. Um beijo produz um som indescritível. Aqueles que ainda insistem em copular, não conseguem. Mas não querem admitir." 14

O ambiente e as regras de convivência são apresentados com frieza e minúcia. A linguagem descritiva e neutra empregada por Beckett dá ao leitor a sensação de que ele observa experiências de laboratório. As criaturas, ou melhor, os "corpos" são tipificados. Entretanto, o narrador não menciona se há oxigênio ou sistemas de ventilação no recinto; menciona apenas que as criaturas respiram com dificuldade, sendo o "silêncio mais forte que todas essas fracas respirações reunidas." ${ }^{15}$ Não há indicação de outras necessidades fisiológicas além da eventual satisfação sexual, infrequente. Não se alimentam, não excretam, não se comunicam verbalmente ao que parece. Alguns agitam-se freneticamente, outros vagam em ritmo

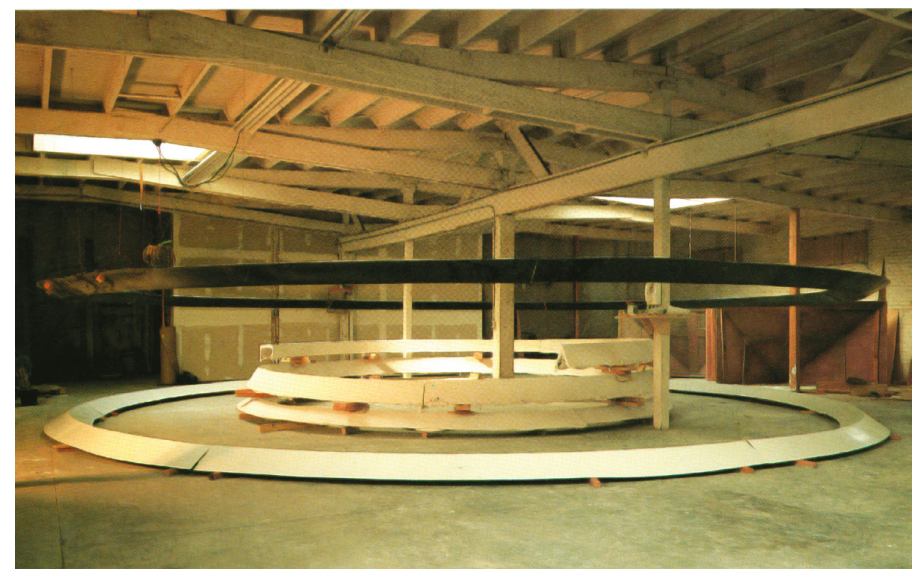

10. Model for Trench and Four Buried Passages, 1977, gesso e fibra de vidro, $\emptyset$ 165, $\emptyset$ 487, $915 \mathrm{~cm} .{ }^{\circledR}$ Bruce Nauman; crédito fotográfico ${ }^{\circledR}$ Frank J. Thomas/ Leo Castelli Gallery. relentado, amortecidos em voltagem rebaixada. São qualificadas por uma condição existencial pautada pela falta (buscadores, ex-buscadores, desistentes), características atribuídas segundo a movimentação dentro do cilindro. Há os que circulam sem parar, há os que às vezes pararam, há os sedentários, há os paralisados $^{16}$.

Os "fulanos" buscam presumivelmente a saída. A hipótese de evasão nem se confirma nem é 12 Adota-se aqui a tradução brasileira realizada por Eloisa Araújo Ribeiro. Cf. BECKETT, Samuel. O
despovoador. In: Mal visto mal dito. São Paulo: Martins Fontes, 2008, p. 3-34.
13 Id., ibidem, p. 24 .
${ }^{14}$ Id., ibidem, p. 6 .
${ }^{15}$ Id., ibidem, p. 34 .
16 Id., ibidem, p. 8 e 9. 


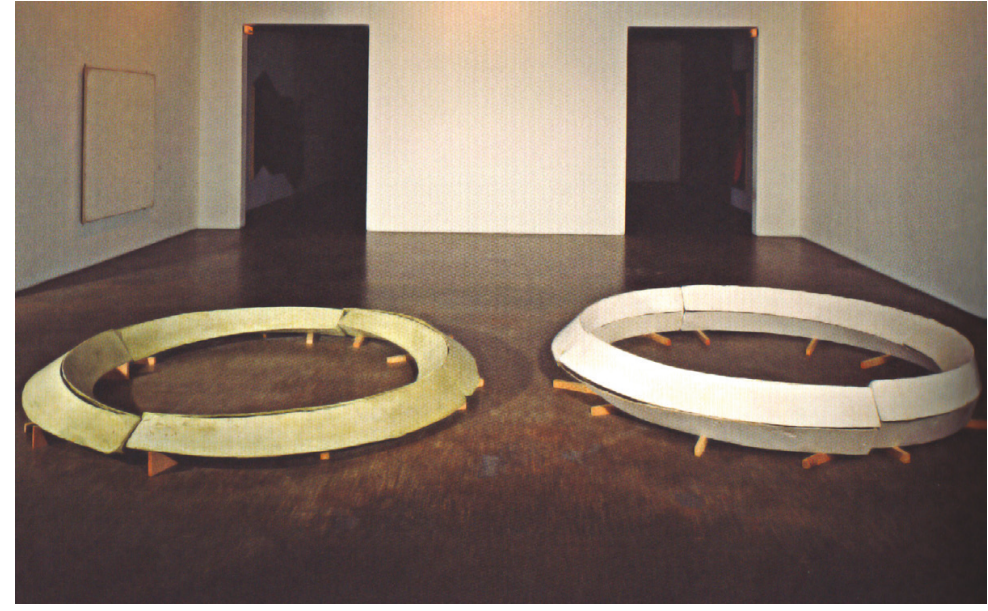

11. Smoke Rings, Models for Underground Tunnels, 1979-1980, gesso e madeira, $\emptyset 340 \mathrm{~cm}$. ${ }^{\circledR}$ Bruce Nauman; crédito fotográfico ${ }^{\circledR}$ Philippe Migeat.

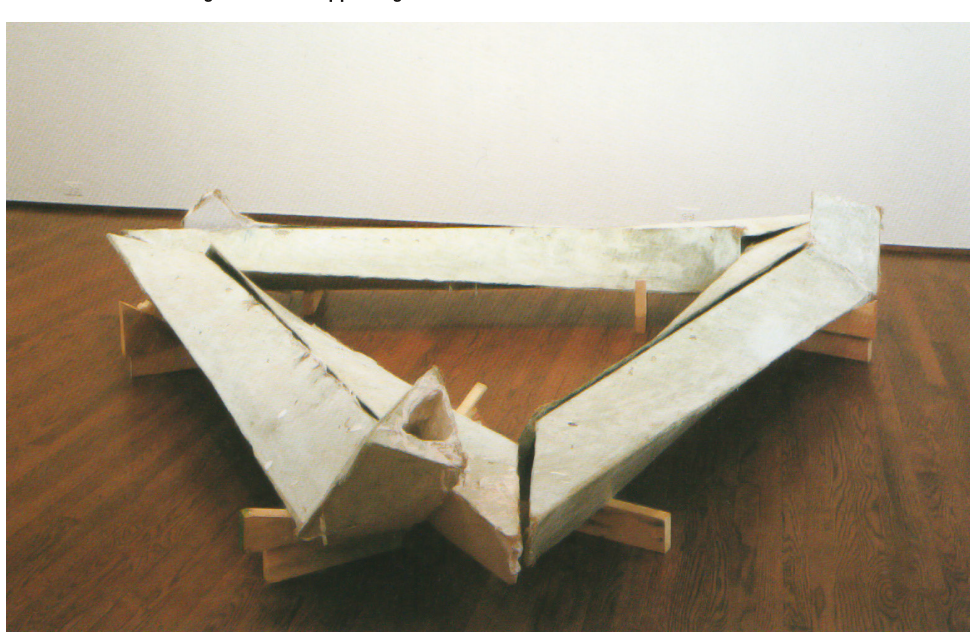

12. Three Dead End Adjacent Tunnels, Not Connected, 1979, gesso e madeira, $63 \times 286 \times 247 \mathrm{~cm}$. () Bruce Nauman; crédito fotográfico ${ }^{\circledR}$ Bevan Davies/ Leo Castelli Gallery. abandonada,

pairando constantemente a incerteza quanto ao êxito da busca: "desde sempre um boato corre ou ainda melhor a ideia ocorre que existe uma saída. Aqueles que já não acreditam nela não estão a salvo de acreditar nela novamente." ${ }^{17}$ Hesitações como essa quebram a estrutura e o ritmo descritivos. Junto às incertezas da fuga há algumas imprecisões infiltradas por todo o texto. Veja-se por exemplo estes trechos: "está portanto entendido que passado um certo prazo difícil de calcular mas que cada um sabe medir com uma diferença de segundos a escada volta a ficar livre"18 ou "a infração não é voluntária mas se deve a uma desregulação temporária de sua ampulheta interior."19 Excertos como esses abalam o rigor e instilam vacilação e vagueza no relato. No cilindro vigora uma variante de imperativo categórico: "uma certa moral engaja a não fazer a outrem o que vindo de sua parte faria mal." ${ }^{20}$ As transgressões são punidas com violência. Os degraus faltantes das escadas, únicos objetos presentes no recinto, são usados para as retaliações, agressão e autodefesa. No espaço milimetricamente apertado, a interação possível é o contato inescapável de corpos que roçam ou espremem suas peles ressequidas pela luz e pelas variações bruscas de temperatura, que passa de um extremo ao outro em segundos. "Obrigados pela penúria de espaço a se colar uns nos outros durante longos períodos eles só mostram ao olhar parcelas de carne confundidas." ${ }^{21} \mathrm{O}$ roçar das peles e a violência são, portanto, as vias habituais de comunicação entre as criaturas.

O efeito desse clima sobre a alma não deve ser subestimado. Mas ela sofre com ele certamente menos do que a pele cujos sistemas de defesa desde o suor até o arrepio são a todo instante contrariados. Ela continua entretanto a se defender mal certo mas de modo honrável com respeito ao olho o qual com a melhor vontade do mundo é difícil não condenar ao cabo se seu esforço à cegueira efetiva. Pois ele próprio pele à

17 Id., ibidem, p. 11.
18 Id., ibidem, p. 13.
19 Id., ibidem, p. 15.
20 Id., ibidem, p. 32.
21 Id., ibidem, p. 33. 


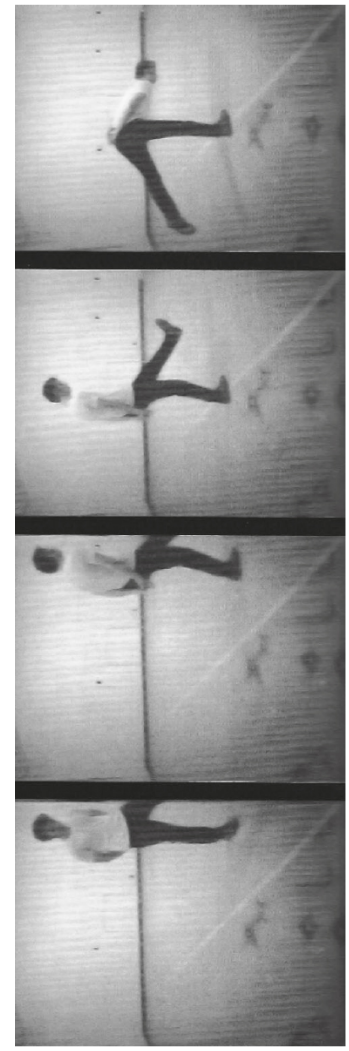

sua maneira sem falar de seus líquidos e pálpebras só tem um adversário. Esse ressecamento do invólucro tira da nudez uma boa parte de seu charme tornando-a cinza e transforma num roçar de urtigas a suculência natural de carne contra carne ${ }^{22}$.

Pois bem, em entrevista concedida em 1982, Bruce Nauman afirmou ter lido $O$ despovoador. $\mathrm{O}$ artista realizava então grandes maquetes de túneis e corredores sem saída e atribuiu a inspiração à leitura, entre outros, do livrinho de Beckett. Realizou, por exemplo, Model for Trench and Four Buried Passages [Modelo para trincheira e quatro passagens enterradas (1977)]; Smoke Rings, Models for Underground Tunnels [Anéis de fumaça, modelos para túneis subterrâneos (1979-1980)]; Three Dead End Adjacent Tunnels, Not Connected [Três túneis sem saída, adjacentes, não conectados (1981)]. Percebia, em suas palavras, "uma conexão poderosa com muitos trabalhos que fiz antes e que me encorajaram na direção dos túneis e do tipo de comentário oblíquo que eles fazem sobre a sociedade."23

Esses trabalhos foram pensados para dimensões arquitetônicas, mas permaneceram como maquetes que contam, geralmente, com versões em mais de um material, alguns em gesso, fibra de vidro e ferro. Trata-se de maquetes enormes que, por vezes, ocupam o espaço expositivo todo. 13. Slow Angle Walk Beckett Cada um dos modelos de túneis circulares da série Smoke Rings tem 3 metros Walk), 1968, vídeo, 60 min.ब e 40 centímetros de diâmetro e comporta-se antes como escultura do que coleção Berkeley Art Museum como maquete. Model for Trench and Four Buried Passages é uma maquete and Pacific Film Archive. para uma intervenção subterrânea ainda maior, um conjunto de círculos

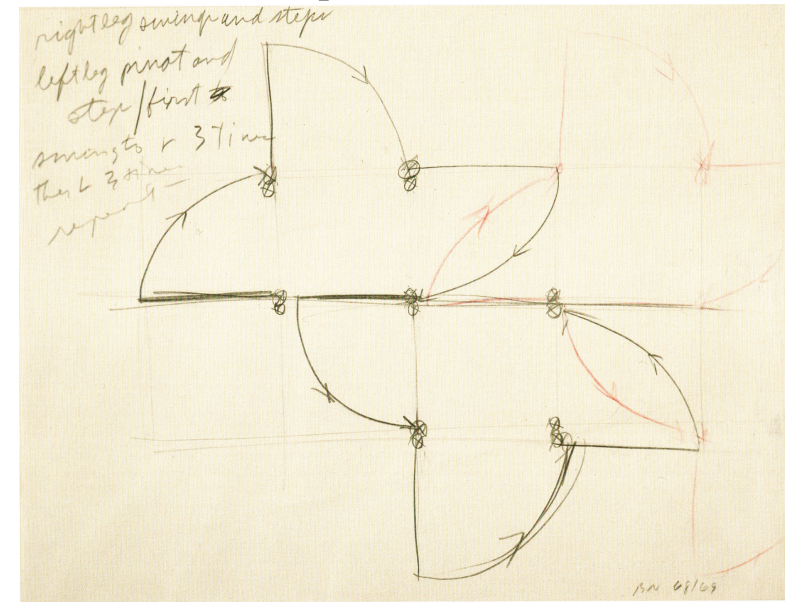

14. Beckett Walk Diagram II, 1968-69, grafite e lapis de cor sobre papel, 21 × 27 $\mathrm{cm} .{ }^{\odot}$ Bruce Nauman; crédito fotográfico ${ }^{\circledR}$ Donald Woodman. concêntricos, fechados, de diâmetros que variam de 1,65 a 9,15 metros. A informação de que se trata de maquetes é dada pelo título ou pela descrição que indica a escala de 1:40. Nauman propõe, portanto, algumas inversões: a maquete assemelha-se a uma escultura na escala do corpo, entretanto deve-se imaginá-la quarenta vezes maior. Ao mesmo tempo em que foram pensadas como intervenções em escala urbana, não adicionariam elementos novos à paisagem uma vez que são maquetes de túneis ou bunkers, ou seja, construções debaixo da terra. Inegável que a série de túneis se aparenta

22 Id., ibidem, p. 29.

23 "[...] when I read this, a very powerful connection to a lot of the work I had done before encouraged me in the direction of the tunnels and the kind of oblique comment they make on society". Cf. KRAYNAK, Janet (Ed.). Op. cit., p. 299.

${ }^{24}$ Cf. CONNOR, Steven. Auf schwankendem Boden. In: GLASMEIER, Michael \& HOFFMANN, Christine (Org.). Op. cit., p. 84 ["die Arbeiten vermitteln eher klaustrophile denn klaustrophobe Züge"]. 
com o ambiente confinado minuciosamente descrito por Beckett. Ambos os artistas propõem espaços de constrição aos quais os corpos, sem muitas alternativas, terminam por adaptar-se, como se transitassem da claustrofobia à "claustrofilia" 24 .

Em pesquisas de arquivo, encontrou-se uma carta inédita que Nauman enviou a Leo Castelli, seu galerista, em 1973, em que sugere que acabara de ler $O$ despovoador ${ }^{25}$. No período, portanto, em que realizava as instalações acompanhadas por textos já comentadas. Logo, conjectura-se que não somente temas como confinamento e contenção do corpo estivessem em pauta em ambas as produções no mesmo momento, mas também um certo sentido de extenuação provocada por condições externas, como a luz intensa que perpassa o livro de Beckett e é empregada nas primeiras instalações de Nauman. É muito provável que $O$ despovoador tenha impressionado Nauman em virtude da neutralidade, crueza e da acurácia descritiva que caracterizam a escrita, uma narrativa bastante peculiar na própria produção de Beckett.

No ano anterior, 1972, Nauman havia concedido uma entrevista em que se declarava leitor assíduo de Beckett desde 1966, e feito especial menção a Molloy - personagem do livro homônimo publicado em 1951 - e aos seus rituais metodicamente elaborados para atividades simples e sem muito sentido, como a transferência em ordem rigorosa de suas pedrinhas de chupar pelos bolsos do $\operatorname{casaco}^{26}$. Watt ${ }^{27}$ talvez tenha inspirado a engenhosa coreografia desenhada e diligentemente executada por Nauman num vídeo captado em seu ateliê, em 1968, intitulado Slow Angle Walk (Beckett Walk) [Caminhada angular lenta (Caminhada Beckett)]. Trata-se de um trabalho em que a câmera de vídeo está disposta de tal modo que, na cena registrada, o protagonista parece caminhar não sobre o piso, mas pela parede. Desempenhando um esforço descomunal, Nauman "anda" vagarosamente por essa parede de maneira bizarra, examinando as minúcias daquela superfície enquanto tenta, a muito custo, manter o equilíbrio numa sequência de passos complicados tanto na execução física quanto nos cálculos mentais que os definem e sustentam.

Primeiro, lança uma das pernas esticada e a paralisa no ar, torce seu tronco em uma meia volta antes de calcar no chão o pé que acabara de erguer; inicia então o próximo passo lançando a outra perna esticada para paralisá-la no ar, torcendo depois o tronco antes de cravála e recomeçar a rotina, mantida por intermináveis sessenta minutos. Sem dúvida, um exercício intrincado que requer perícia e concentração, pois ao mesmo tempo em que alarga a trajetória expandido-a para as bordas, Nauman aplica uma tensão extrema às passadas para se conservar no eixo, exigindo que todo o corpo reverbere a pressão dos pés contra o solo. Seguindo pormenorizadamente esse padrão autoimposto de gestos, Nauman avança em ritmo refreado,

\footnotetext{
${ }^{25}$ A carta foi datada de 9 de novembro de 1973 e nela o artista detalha as instruções para a montagem de Floating Room [Recinto Flutuante (1972)]. A pesquisa foi realizada nos Arquivos de Arte Americana do Instituto Smithsonian de Washington, em 2012.

26 "There's a passage in Beckett's Molloy about transferring stones from one place to another, the pockets of an overcoat, without them getting mixed up. It's elaborate without any point". Cf. SCHAFFNER, Ingrid. Bruce Nauman through Samuel Beckett. In: MORGAN, Robert C. (Ed.). Bruce Nauman. Baltimore: The Johns Hopkins University Press, 2002, p. 167.

27 Personagem do romance homônimo de Beckett, publicado em 1953, que além de outras esquisitices, anda de modo extravagante. Sem dobrar seus joelhos, Watt segue em linha reta exaurindo todo o espaço: depois de uma inclinação inaugural, uma pequena queda adiante, Watt vai em direção ao leste, girando o tronco em direção ao norte e jogando a perna direita em direção ao sul e, em seguida, o tronco em direção ao sul e a perna esquerda ao norte, e assim sucessivamente. Cf. BECKETT, Samuel. Watt. Lisboa: Assírio \& Alvim, 2005, p. 34.
} 
sem culminação ou desfecho. Surge, nessa toada, um contrassenso: o caminhante se movimenta muito para efetivamente se deslocar pouco. Definitivamente, uma caminhada Beckett.

Nessa época, Nauman filmava-se sozinho no ateliê vazio executando à exaustão atividades banais como andar, dançar, bater os pés vigorosamente no chão, arremessar bolinhas de borracha contra as paredes. Depurando movimentos simples em frações mínimas ou realçando gestos ou poses particulares, Nauman obtinha uma espécie de dilação do tempo implicado em cada tarefa. Esses filmes $16 \mathrm{~mm}$ e vídeos estabelecem relações entre a intensidade de cada ação ou de cada inação prolongada e a fadiga surgida da persistência ou da circularidade de uma postura ou de uma atuação, isto é, uma relação tensa entre duração e repetição. Reservatórios de um tempo distendido, a duração parece interminável, mas as ações têm um desenrolar preciso. No mais das vezes, são elaboradas para propulsar ritmos incessantes que, embora sujeitos às variações de cadência, não são levados a termo. Revoga-se uma lógica narrativa que implicaria em culminação e conclusão; não há síntese, portanto.

Deve-se ressaltar que, na produção de Nauman, o corpo comparece de modo peculiar: nem um corpo totalmente livre tampouco domesticado pelas exigências de funcionalidade. Trata-se de um corpo que se lança em atividades insólitas e que nelas e com elas perde tempo. Mas também se trata de um repertório de atividades que exige um desempenho preciso, uma extrema concentração e considerável motricidade e treinamento: o corpo está sempre tensionado, pronto para disparar o próximo movimento, que se encadeia numa série usualmente extensa e desgastante pelo esforço de repetição requerido, como se estivesse preso em um momento distendido e perpetuado para o qual não há desenlace.

Circularidade como mecanismo para promover experiências de saturação e extenuação e uma disciplina de contenção no tratamento do corpo são procedimentos que aproximam a obra de Nauman à de Beckett. Estabelecer sequências precisas e executá-las em conformidade com um método prévio é uma forma privilegiada de regular o tempo nas duas produções. A contenção, o vagar, a celeridade ou o frenesi implicados nas rotinas, por mais extravagantes que sejam, dilatam ou comprimem as durações, desabituando a experiência. Processos de simplificação, reiteração incessante de padrões e de permutação de elementos restritos como formas de regular a percepção do transcurso do tempo também marcam os dois percursos. Beckett e Nauman recorrem às enumerações e combinatórias, aludindo aos métodos e à precisão matemático-musical e, ao mesmo tempo, instilam variações tênues nos mecanismos repetitivos que conjuram, sem nunca cumprir, a promessa de ruptura dos ciclos.

Beckett e Nauman logram o máximo efeito com mínimos recursos, comunicam extraindo muito de quase nada. Assemelham-se na simplificação e na crueza da linguagem (aqui, tendo em consideração os textos beckettianos pautados pelo empobrecimento paulatino da linguagem, nos quais, nas palavras do autor, "a linguagem é mais eficientemente empregada quando mal empregada" ${ }^{28}$ ). Assemelham-se também na precisão descritiva para apontar situações vagas e lugares implausíveis, conforme se argumentou. Interessa-lhes tensionar a linguagem no limite de sua eficácia comunicativa, quando falha ou se torna pouco eficiente. $\mathrm{O}$

${ }^{28}$ Excerto da conhecida carta enviada a Axel Kaun, em 1937. Conferir tradução de Fábio de Souza Andrade. Cf. ANDRADE, Fábio de Souza. Samuel Beckett: o silêncio possível. São Paulo: Ateliê Editorial, 2001, p. 169. 
desafio é manter, a um só tempo, coesão e ambiguidade. Para atingir a opacidade pretendida, desencaixam as palavras dos contextos habituais de uso, realçam entonações inadequadas ao significado, à utilização cotidiana de um termo, então infiltram nos discursos elementos ardilosos de disrupção, injetando metodicamente doses precisas de gracejos, sarcasmo ou crueldade que corroem qualquer hábito cristalizado.

Além de procedimentos comuns, abordam temas relacionados à crueldade, à frustração, ao fracasso e ao não aprendizado. O procedimento crucial é o da repetição infindável e a perversão maior é a simulação do desenlace ou da interrupção dos ciclos. Um dos aspectos mais provocativos é abordar de modo conciso e despretensioso os "grandes temas", tais como vida, morte, sexo, violência, intimidade, reduzindo-os a uma dimensão constatável.

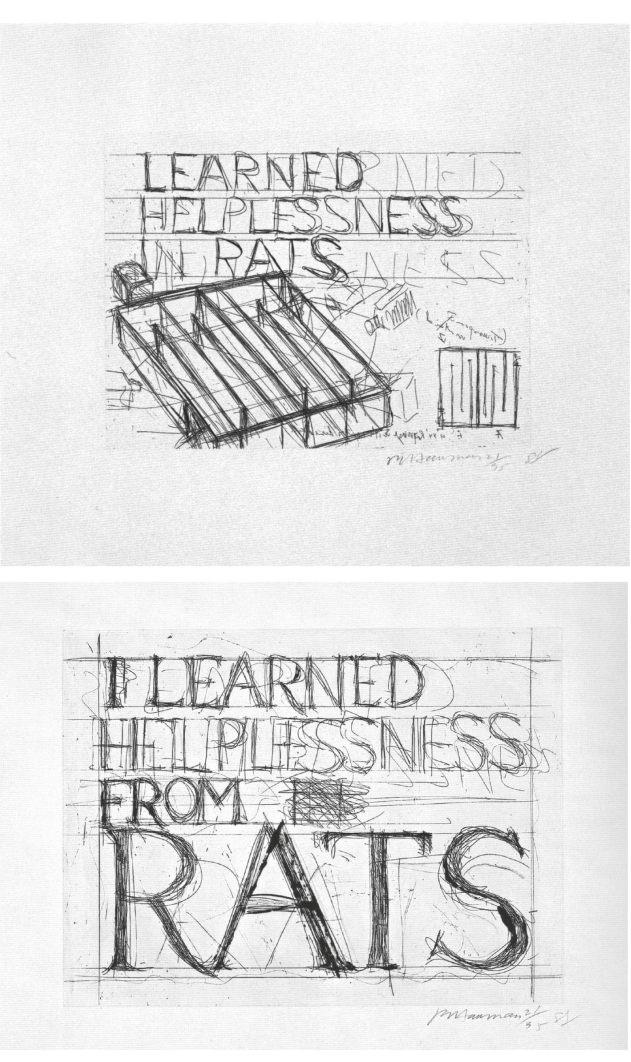

15. Learned Helplessness in Rats, 1988 , gravura, $39,4 \times 45,7 \mathrm{~cm}$. Learned Helplessness from Rats, 1988, gravura, $39,4 \times 45,7 \mathrm{~cm} .^{(}$ Bruce Nauman; crédito fotográfico ${ }^{\circledR}$ Stefan Altenburger.
Empenham-se em detectar e expor o aspecto mais corriqueiro de tais temas, que talvez existam com mais evidência em uma dimensão mais rebaixada. Propõem inventários da "condição humana" nos quais se igualam faculdades, aspirações, sentimentos e necessidades fisiológicas.

Tornar as coisas mais simples e menos importantes é o postulado para os trabalhos nos quais Nauman discute, segundo suas próprias palavras, a "condição humana". A parte frustrante da condição humana, que fique claro:

Eu sei que há artistas que funcionam em relação à beleza [...] são movidos por coisas bonitas e veem aí o seu papel: dar ou fazer coisas bonitas para outras pessoas. Eu não trabalho dessa forma. [...] O sol, flores, paisagens, este tipo de coisa não me move a fazer coisa alguma. Eu só quero deixá-las em paz. Meu trabalho tem sido a respeito de ficar frustrado com a condição humana. E sobre como as pessoas podem ser cruéis umas com as outras. Não é que ache que possa mudar isso, trata-se apenas da parte frustrante da história humana ${ }^{29}$

Dele é a frase "I learned helplessness from the rats", "eu aprendi o desamparo com os ratos", título de uma instalação e sentença que aparece em desenhos e gravuras. A frase evidencia o teor cáustico de sua obra. Risos malévolos de palhaços cruéis como resposta a gritos de pavor, ruídos infernalmente agudos do atrito de moldes giratórios de carcaças de animais deformados contra o chão, uma briga de casal que termina em morte, um desenho de um gato empalado, joguinhos infantis contagiados de violência e de sexo violento, rituais de dominação com pitadas de escatologia. O catálogo da parte frustrante da história humana é, de fato, um catatau.

29 "I know that there are artists who function in relation to beauty [...] They are moved by beautiful things and they see that as their role: to provide or make beautiful things for other people. I don't work that way. [...] Sunsets, flowers, landscapes; these kinds of things don't move me to do anything. I just want to leave them alone. My work comes out being frustrated about the human condition. And about how people can be cruel to each other. It's not that I think I can change that, but it's just such a frustrating part of human history". Cf. KRAYNAK, Janet (Ed.). Op. cit., p. 332-333. 